\title{
Impurity sources and fluxes in W7-X: from the plasma-facing components to the edge layer
}

\author{
E. Wang ${ }^{1}$, S. Brezinsek ${ }^{1}$, S. Sereda ${ }^{1}$, B. Buttenschön ${ }^{2}$, T. Barbui ${ }^{3}$, C. P. Dhard ${ }^{2}, M$. \\ Endler $^{2}$, O. Ford ${ }^{2}$, E. Flom ${ }^{3}$, K. C. Hammond ${ }^{2}$, M. Jakubowski², M. Krychowiak' ${ }^{2}$ P. \\ Kornejew $^{2}$, R. König' ${ }^{2}$, Y. Liang ${ }^{1}$, M. Mayer ${ }^{6}$, D. Naujoks ${ }^{2}$, O. Neubauer ${ }^{1}$, J. \\ Oelmann ${ }^{1}$, M. Rasinski ${ }^{1}$, V. R. Winters ${ }^{3}$, A. Goriaev ${ }^{4}$, T. Wauters ${ }^{4}$, Y. Wei ${ }^{5}$, D. \\ Zhang ${ }^{2}$, and the W7-X team ${ }^{2, b}$
}

\author{
${ }^{1}$ Forschungszentrum Jülich GmbH, Institut für Energie- und Klimaforschung - Plasmaphysik, Partner of \\ the Trilateral Euregio Cluster (TEC), Jülich, Germany \\ ${ }^{2}$ Max-Planck-Institut für Plasmaphysik, Greifswald, Germany \\ ${ }^{3}$ University of Wisconsin-Madison, Madison WI, USA \\ ${ }^{4}$ Laboratory for Plasma Physics, LPP-ERM/KMS, Partner of the Trilateral Euregio Cluster (TEC), \\ Brussels, Belgium \\ ${ }^{5}$ Southwestern Institute of Physics, Chengdu, China \\ ${ }^{6}$ Max-Planck-Institut für Plasmaphysik, Garching, Germany \\ ${ }^{b}$ W7-X Team are listed in Nucl. Fusion 57, 102020 (2017).
}

E-mail: e.wang@fz-juelich.de

Received xxxxxx

Accepted for publication $\mathrm{xxxxxx}$

Published xxxxxx

\section{Abstract}

Wendelstein 7-X (W7-X) is a nearly full-carbon machine with graphite divertors, baffles and shields in Operation Phase 1.2b (OP 1.2b). Divertor spectrometer measurements showed that an amount of helium and oxygen impurities existed in the predominately hydrogen plasma, which resulted in a high carbon impurity level by enhanced physical and chemical sputtering by these impurities in comparison with the pure impinging proton yields. In order to improve the wall conditions, especially to reduce the oxygen content, boronizations were applied in OP1.2b. After the boronization, an oxygen decrease by more than an order of magnitude was observed. Helium disappeared in comparison with OP1.2a due to reduced application of helium wall conditioning after introduction of boronizations. The overall radiation normalized to line integrated density was reduced by a factor of six.

In addition, local $\mathrm{CH}_{4}$ injection was applied in the divertor in order to quantify the chemical sputtering by hydrogen on divertor plates. The experimentally determined effective $\mathrm{D} / \mathrm{XB}$ of the A-X band of $\mathrm{CH}$ resulting from $\mathrm{CH}_{4}$ was $\left[\frac{D}{X B}\right]_{A^{2} \Delta \rightarrow X^{2} \Pi}^{C H_{4} \rightarrow C H}=16$ at $\mathrm{T}_{\mathrm{e}} \approx 20 \mathrm{eV}$ and $\mathrm{n}_{\mathrm{e}} \approx 5 \mathrm{e}^{2} 8 \mathrm{~m}^{-}$ 3 . It was applied to determine the hydrocarbon fluxes and further to deduce the particle flux ratio $\Gamma^{\mathrm{CH} 4} / \Gamma^{\mathrm{H}}$ on divertor plates.

Keywords: impurity, carbon chemical sputtering, $\mathrm{CH}_{4}$ injection, W7-X

\section{Introduction}

One of the key issues to achieve long stable discharges in fusion devices is the minimization of the erosion source of 
plasma-facing components which ensures a long lifetime of components as well as to ensure a low impurity concentration in the plasma. Key processes governing the erosion of graphite-based components are physical and chemical sputtering [1]. The physical sputtering results from elastic energy transfer from incident particles to target atoms. It depends on a number of parameters such as the mass ratio of incident particles to surface atoms, particle energy, and flux density. Therefore, the heavy mass impurities usually have much larger physical sputtering yields compared to the hydrogen produced physical sputtering yield. The selfsputtering also could have a very high yield, e.g. $Y \geq 0.5$ for carbon self-sputtering with normal incident ions. It is to be noted that there is a threshold energy for the physical sputtering. The chemical sputtering is a complicated multistep process that depends on the particle energy and flux, surface temperature, and material properties. For carbon, chemical reactions with incident hydrogen ions lead to the formation of volatile hydrocarbon molecules on the surface and later release to the plasma in a multistep process. The presence of oxygen in plasma could significantly enhance the chemical erosion in carbon machine through the formation of $\mathrm{CO}$ and $\mathrm{CO}_{2}$ which are the sources for both carbon and oxygen impurities in plasma [2]. The chemical sputtering yield due to oxygen is close to unity even at room temperature. In order to control the oxygen content, getting techniques to bind the oxygen strongly on the surface have been developed, such as boronization [3]. In fusion devices, the gross erosion rates owing to physical and chemical sputtering processes have been investigated extensively by optical emission spectroscopy observing the spectral emission of C I, C II, CH $\mathrm{A}-\mathrm{X}$ band and $\mathrm{C}_{2} \mathrm{~d}-\mathrm{a}$ band in e.g. TEXTOR [4], JET [5], DIIID [6] and ASDEX Upgrade [7] when operating with graphitebased plasma facing components.

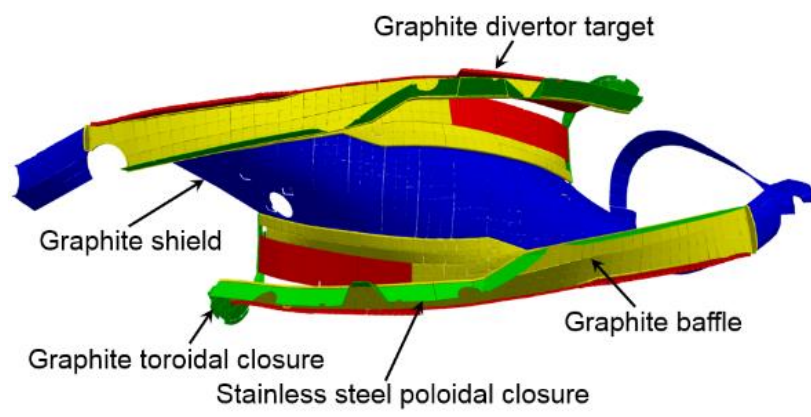

Figure 1. One fifth of the circumference of W7-X with the inertially cooled plasma-facing components installed in OP1.2a

W7-X is a large advanced stellarator which aims at the long steady-state operation with the high plasma performances. Therefore, reducing the erosion of plasma-facing components to prolong its life and avoiding the impurity concentration in the core plasma is a critical issue. In OP $1.2 \mathrm{~b}, \mathrm{~W} 7-\mathrm{X}$ operated in island divertor configurations with the most of plasma facing components made of uncooled graphite, i.e. graphite divertor plates, baffles, shields, and toroidal closures as shown in Fig.1. The poloidal closures and outer panels (not shown in Fig.1) were made of stainless steel. The strongest plasmasurface interaction region is located at the strike lines on divertor plate, the location of which on divertor plates depended on the main magnetic configuration [8]. In order to improve the wall condition, three basic wall conditioning techniques were applied, i.e. baking before first plasma, glow discharge cleaning before and during campaign and helium ECRH discharge cleaning [9]. However, the helium and oxygen impurities in plasma were still considerable, which resulted in high carbon impurity content by enhanced erosion on plasma-facing components. Therefore, boronizations were applied to reduce the oxygen content in OP1.2b with the first one 5 weeks after first plasma and the other two after about one month of operation each. After boronization, significant reduction of impurities was observed (section 3.1). In order to in-situ quantify the carbon chemical erosion by hydrogen, $\mathrm{CH}_{4}$ injection was applied to deduce the photon efficiencies of the A-X band of its radical $\mathrm{CH}$ (section 3.2).

\section{Experimental set-up}

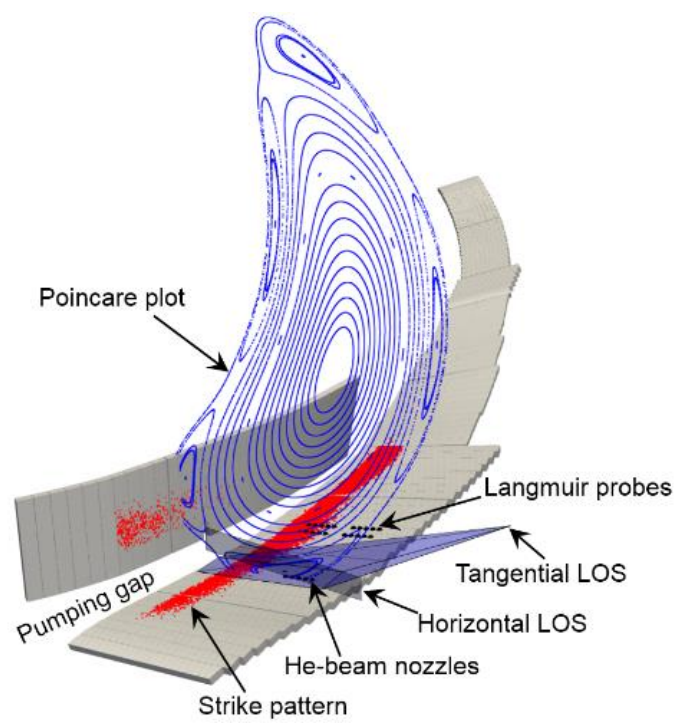

Figure 2. Standard divertor magnetic configuration. The main plasma is surrounded by 5 independent islands which are opened by divertor plates. 5 helium-beam nozzles and 20 Langmuir probes are installed in the horizontal divertor plate to measure edge plasma parameters. Tangential and horizontal LOS are attached to an overview spectroscopy and a high spectral resolution spectrometer (SP2750), respectively. The horizontal LOS includes 27 channels with a spatial resolution $5 \mathrm{~mm}$ in radial direction.

$\mathrm{W} 7-\mathrm{X}$ has a major plasma radius of $5.5 \mathrm{~m}$ and a minor radius of $0.5 \mathrm{~m}$. It consists of 50 non-planar superconducting coils and 20 planar superconducting coils to produce the basic magnetic configurations, i.e. standard divertor configuration $\left(\mathrm{l}_{\mathrm{a}}=\mathrm{m} / \mathrm{n}=5 / 5, \mathrm{l}_{\mathrm{a}}\right.$ : rotational transform at last close flux surface 
) low/high iota $\left(\mathrm{l}_{\mathrm{a}}=\mathrm{m} / \mathrm{n}=5 / 6,5 / 4\right)$, low/high mirror $\left(\mathrm{l}_{\mathrm{a}}=\mathrm{m} / \mathrm{n}=5 / 5\right)$, and inward/outward shifted $\left(\mathrm{l}_{\mathrm{a}}=\mathrm{m} / \mathrm{n}=5 / 5\right)$ configurations [8]. In addition, 10 control coils are used to slightly change the size of boundary islands and footprint position on divertor plates. In OP1.2b, ten test divertor units made of graphite, two in each period of the fivefold symmetric device, were installed. This open divertor structure allowed an effective particle and energy exhaust for a wide range of plasma and magnetic parameters. Here in this paper, we only focus on the standard divertor configuration which has 5 independent edge islands opened by divertor plates. A Poincare plot and the position of its strike lines on divertor targets are shown in Fig.2.

In order to study the impurity behaviors in edge plasma, a set of spectroscopic diagnostics have been installed on W7-X. Here, we mainly report on the results obtained from two divertor spectrometers as shown in Fig.2. The first one was a tunable, fiber-coupled Czerny-Turner spectrometer (Teledyne Princeton Instruments: SP2750) with a focal length $750 \mathrm{~mm}$. This spectrometer had three gratings, i.e. $300 \mathrm{~g} / \mathrm{mm}, 1200$ $\mathrm{g} / \mathrm{mm}$ and $2400 \mathrm{~g} / \mathrm{mm}$ with a wavelength coverage of $\Delta \lambda=58$ $\mathrm{nm}, 13 \mathrm{~nm}$ and $4.2 \mathrm{~nm}$ for each grating position. The camera was a frame transfer CCD camera (Teledyne Princeton Instruments: ProEM-HS 1024B) with 1024 x 1024 pixels (pixel size: $13 \times 13 \mu \mathrm{m}$ ). The spectral resolution was $\Delta \lambda_{\text {FWHM }}$ $=0.23 \mathrm{~nm}, 0.06 \mathrm{~nm}$ and $0.03 \mathrm{~nm}$ at $435.8 \mathrm{~nm}$ using gratings $300 \mathrm{~g} / \mathrm{mm}, 1200 \mathrm{~g} / \mathrm{mm}$ and $2400 \mathrm{~g} / \mathrm{mm}$ with an entrance slit width $\mathrm{W}_{\text {slit }}=50 \mu \mathrm{m}$. This spectrometer was attached to AEI51 port using 27 quartz fibers with a diameter $200 \mu \mathrm{m}$ (numerical aperture $\mathrm{NA}=0.22$ ), lines of sight (LOS) of which were parallel to the horizontal divertor plate with a spatial resolution $5 \mathrm{~mm}$ as shown in Fig.2. The other one was an overview spectroscopy (Avantes: ULS2048L) which was attached to the endoscope using quartz fibers $(\mathrm{NA}=0.22)$ with a diameter $800 \mu \mathrm{m}$ [10], LOS of which was tangential as shown in Fig.2. This overview spectroscopy had 5 build-in compact spectrometers which covered a wide wavelength range of $300 \mathrm{~nm}-1000 \mathrm{~nm}$ with moderate spectral resolution. In addition, one thermal He-beam system with five injection nozzles was installed on divertor plates which could inject helium to measure edge electron density and temperature profiles [11], and other gases for different researches, e.g. $\mathrm{H}_{2}$ for density feedback, $\mathrm{N}$ and $\mathrm{Ne}$ for edge radiation cooling, and $\mathrm{CH}_{4}$ to quantify carbon chemical erosion. 20 Langmuir probes covering partial strike lines were installed on divertor plate to measure ion saturation current, electron density, and temperature [12]. Their relative positions are shown in Fig.2.

\section{Results and discussion}

\subsection{Impurity identification}

A typical spectrum of hydrogen plasma measured before boronization is shown in Fig.3. The identified spectral lines indicated that the primary impurities in edge plasma were He, $\mathrm{C}$ and $\mathrm{O}$. Before boronization, helium glow discharge cleaning was used before and during campaign and helium ECRH discharge cleaning was used during campaign to improve wall conditions. The residual helium cannot be removed completely by following serial hydrogen discharges, which was proved by the strong helium lines shown in Fig.3. The oxygen spectrum was extremely strong as well, especially in the wavelength range of $350 \mathrm{~nm}-450 \mathrm{~nm}$. When energetic oxygen ions impact to a pure carbon surface, oxygen is potentially retained up to a concentration of about 0.25 oxygen per carbon within the implantation zone. The saturation concentration decreased with increasing carbon temperature and decreasing impact energy. After saturation is reached, it is re-emitted in the form of $\mathrm{CO}$ and $\mathrm{CO}_{2}$ with a yield close to unit even at room temperature. The oxygen may also recycle many times before finally being buried in a surface or removed by

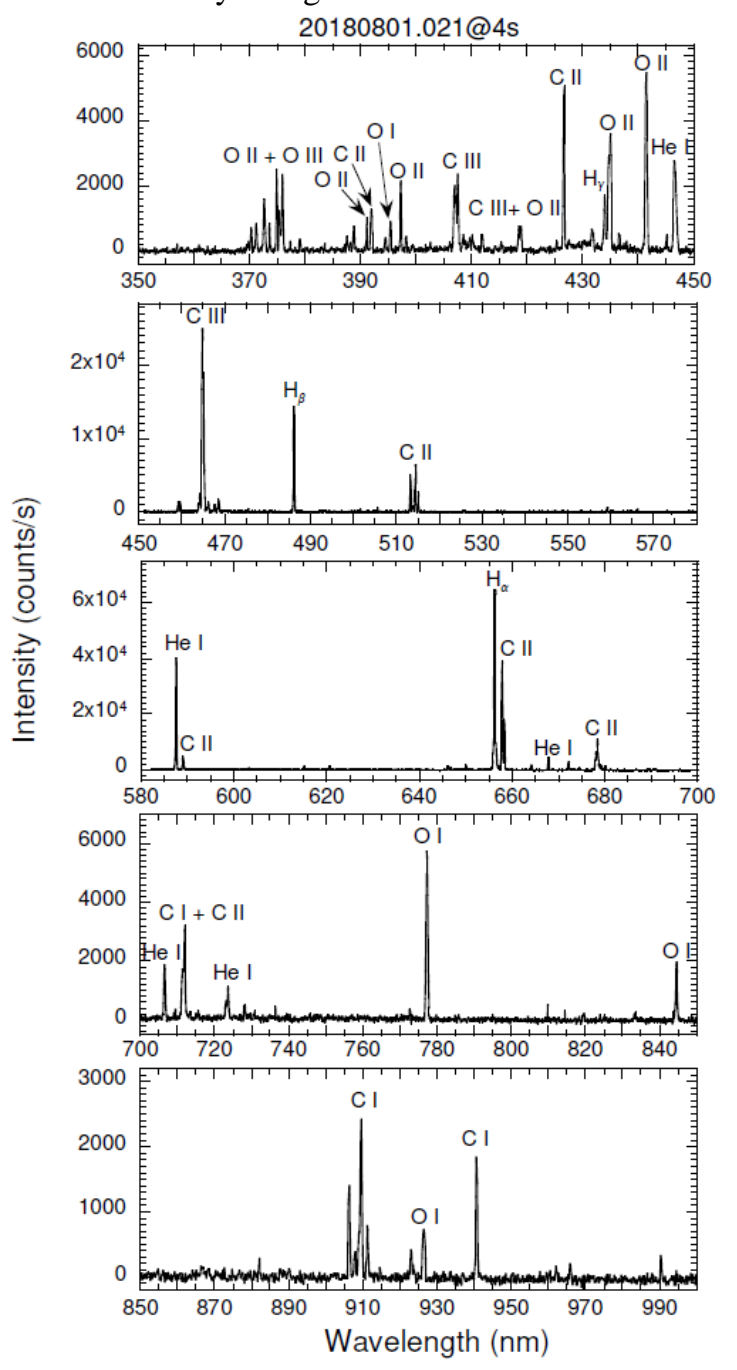

Figure 3. Typical hydrogen plasma spectrum in $350 \mathrm{~nm}-$ $1000 \mathrm{~nm}$ measured by divertor overview spectrometer before $1^{\text {st }}$ boronization. 
the pumps as a gas. For carbon chemical sputtering by oxygen ions, there is no detectable spectrum from its molecular products in the visible wavelength range. However, the residual gas analyzer diagnostic could give certain information about it. In W7-X, the original oxygen came from the vapor contained in the fine grain graphite and the content level of oxygen in plasma showed a same tendency with the temperature of divertor plates. The existence of $\mathrm{He}$ and $\mathrm{O}$ in plasma significantly enhanced the physical and chemical erosion on graphite plasma-facing components, which resulted in high carbon level in plasma as well.

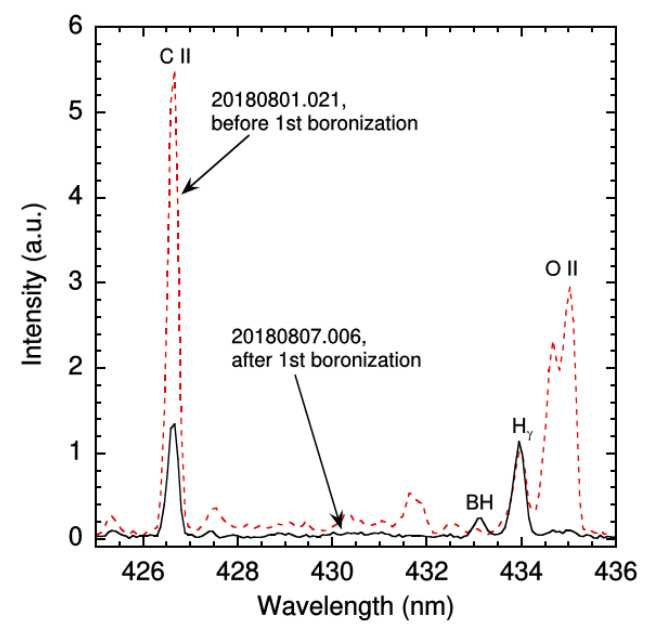

Figure 4. Impurity comparison before and after first boronization measured by divertor overview spectrometer (tangential LOS). These two spectrums are normalized to $\mathrm{H} \gamma$ Carbon and oxygen are reduced significantly.

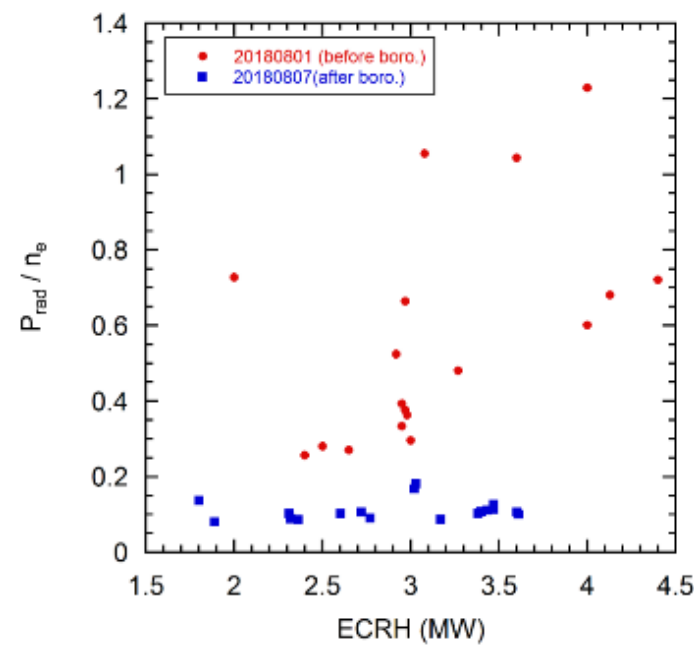

Figure 5. Comparison of overall radiation before and after first boronization measured by bolometer. The radiation is normalized to the line integrated density. After first boronization, total radiation is reduced significantly.

In order to improve the wall condition especially control the oxygen, boronizations were applied in OP1.2b. The boronization was demonstrated by injecting $10 \% \mathrm{~B}_{2} \mathrm{H}_{6}$ in helium glow discharge and this produced amorphous boroncontaining carbon films a-C/B:H. The prime advantage of the boronization films was their ability to getter oxygen due to the incorporated boron atoms and their superior resistance to chemical erosion by thermal and energetic hydrogen species. After first boronization, the carbon and oxygen contents were reduced significantly as shown in Fig.4. C II was reduced by about $75 \%$ due to the coverage of boron films on graphite plasma facing components. O II nearly disappeared, which means the oxygen contribution to carbon erosion vanished. The overall radiation measured by bolometer decreased by about six times as shown in Fig.5 [13]. The total radiation before boronization was quite larger and more discrete than the radiation after boronization. After boronization, helium glow discharges for improving wall condition were not necessary any more. Therefore, helium also disappeared after boronization.

\section{2 $\mathrm{CH}_{4}$ injection experiment}

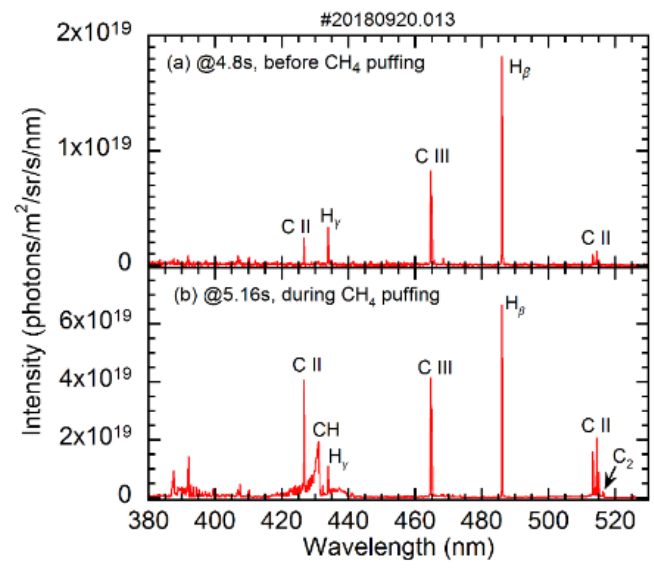

Figure 6. Spectrum measurement by overview spectrometer. $\mathrm{CH}_{4}$ is puffed using the fifth nozzle of helium beam system which is closest to pumping gap as shown in Fig.2 into a steady-state hydrogen discharge with constant injecting power $\left(P_{E C R H}=4.7 M W\right)$ and line integrated density $\left(\right.$ ne $\left.=6 e 19 \mathrm{~m}^{-2}\right)$.

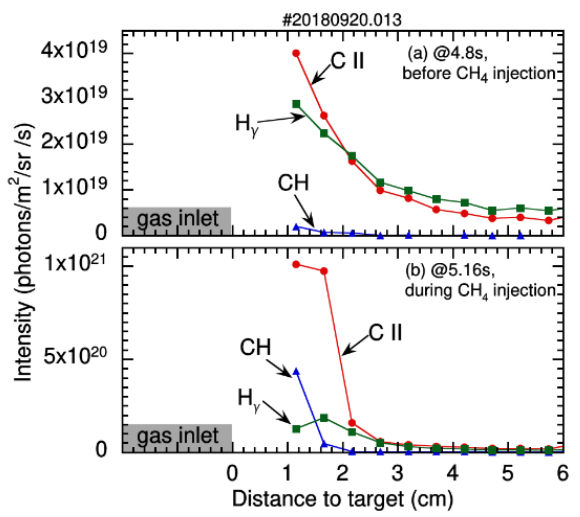

Figure 7. $\mathrm{CH}, \mathrm{H}_{\gamma}$ and $\mathrm{C}$ II penetration depth in radial direction before (a) and during (b) $\mathrm{CH}_{4}$ injection measured by SP2750 spectrometer (horizontal LOS). 
The photon fluxes of atomic or ions lines can be transferred into particle fluxes by means of inverse photon efficiencies $\mathrm{S} / \mathrm{XB}$ values ( $\mathrm{S}$ stands for ionization rate, $\mathrm{X}$ for excitation rate and $\mathrm{B}$ for branching ratio of the observed transition; In case of molecules D/XB replacing ionization by decomposition) [14]. The $\mathrm{S} / \mathrm{XB}$ values could be obtained from the atomic data and analysis structure (ADAS) database for given electron density and temperature [15]. The disadvantage of this way is that the spectrum measurements are usually line integrated and local plasmas parameters are not always measured. The other method to get $\mathrm{S} / \mathrm{XB}$ values is to inject dedicated gas with knowing influx. The gas injection influx should be high enough to get adequate photon fluxes for spectrometers and low enough to minimize local plasma disturbances. In this part, we will focus on this method.

The total carbon flux is $\Gamma_{c}^{\text {total }}=\Gamma_{c}^{\text {chem }}+\Gamma_{c}^{\text {phys }}$ which can be deduced by observation of carbon ion spectrum, i.e. C II. The chemical erosion on carbon plasma-facing components leads to the production of methane $\left(\mathrm{CH}_{\mathrm{x}}\right.$ with $\left.\mathrm{x} \leq 4\right)$, ethane $\left(\mathrm{C}_{2} \mathrm{H}_{\mathrm{y}}\right.$ with $\left.\mathrm{y} \leq 6\right)$, propane family $\left(\mathrm{C}_{3} \mathrm{H}_{\mathrm{z}}\right.$ with $\left.\mathrm{z} \leq 8\right)$ and heavier hydrocarbons. Therefore, the carbon flux contributed from chemical erosion can be expressed by $\Gamma_{c}^{c h e m}=\Gamma_{c}^{C H_{x}}+$ $2 \Gamma_{c}^{C_{2} H_{y}}+3 \Gamma_{c}^{C_{3} H_{z}}+\cdots$. The heavier hydrocarbons usually have much less production rate than the lighter hydrocarbons. The detectable spectrum in visible spectral range for hydrocarbon and their radicals are mainly $\mathrm{CH}$ Gerö band $\left(A^{2} \Delta \rightarrow X^{2} \Pi\right), \mathrm{CH}^{+}$Douglas-Herzberg band $\left(A^{1} \Pi \rightarrow X^{1} \Sigma^{+}\right)$ and $\mathrm{C}_{2}$ Swan band $\left(d^{3} \Pi_{g} \rightarrow a^{3} \Pi_{u}\right)$ which mainly represent $\mathrm{CH}_{\mathrm{x}}$ and $\mathrm{C}_{2} \mathrm{H}_{\mathrm{y}}$.

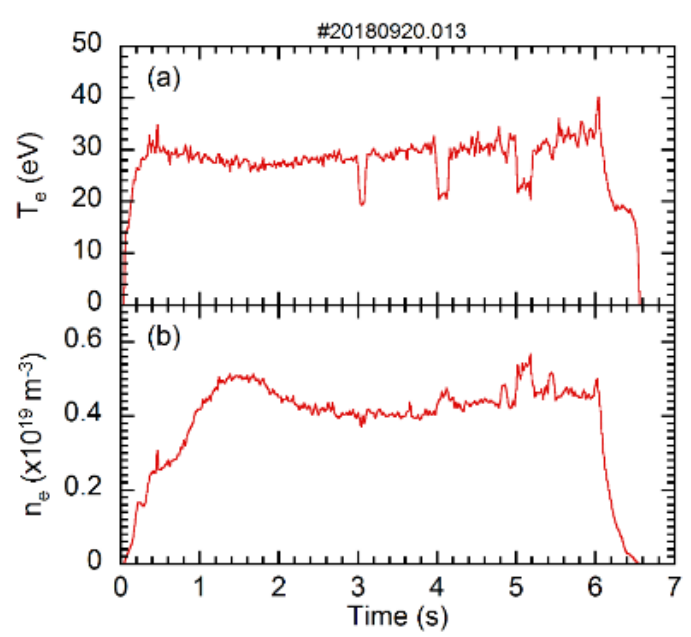

Figure 8. Electron temperature (a) and density (b) measured by Langmuir probes as shown in Fig.2. $\mathrm{CH}_{4}$ is injected at $3 \mathrm{~s}$, $4 \mathrm{~s}$ and $5 \mathrm{~s}$ with a injection length $100 \mathrm{~ms}, 150 \mathrm{~ms}$ and $200 \mathrm{~ms}$.

In OP1.2b, $\mathrm{CH}_{4}$ with a back pressure 250 mbar was injected using the fifth nozzle of helium beam system which was closest to the pumping gap as shown in Fig. 2 into a steadystate hydrogen discharge with constant injecting power
$\left(\mathrm{P}_{\mathrm{ECRH}}=4.7 \mathrm{MW}\right)$ and constant line integrated density $\left(\mathrm{n}_{\mathrm{e}}=6 \mathrm{e} 19\right.$ $\mathrm{m}^{-2}$ ). The $\mathrm{CH}_{4}$ influx was $2.5 \mathrm{e} 20$ molecules/s and leaded to local perturbation and some cooling. The reference spectrum prior to the $\mathrm{CH}_{4}$ injection is shown in Fig.6(a) and consists of $\mathrm{H}_{\beta}, \mathrm{H}_{\gamma}, \mathrm{C}$ II and C III in the wavelength range $380 \mathrm{~nm}-530$ nm. During $\mathrm{CH}_{4}$ injection, all the hydrogen and carbon lines became much stronger due to the dissociation of $\mathrm{CH}_{4}$, and band emission of $\mathrm{CH}$ and $\mathrm{C}_{2}$ appeared as shown in Fig.6(b). The accompanying emission of the Swan band of $\mathrm{C}_{2}$ representing heavier hydrocarbon radicals was also measured during $\mathrm{CH}_{4}$ injection in other fusion devices [4]. The potential explanation is: a fraction of the injected $\mathrm{CH}_{4}$ is locally deposited and immediately re-eroded in the formation of heavier hydrocarbon [4], or the $\mathrm{CH}_{4}$ reacts with carbon divertor plate to form heavier hydrocarbons, such as $\mathrm{C}_{2} \mathrm{H}_{4}$ [16]. Fig. 7 shows the penetration depth of $\mathrm{CH}, \mathrm{H}_{\gamma}$ and $\mathrm{C}$ II before and during $\mathrm{CH}_{4}$ injection. Before $\mathrm{CH}_{4}$ injection, the $\mathrm{CH}$ molecules, $\mathrm{C}^{0}$ and $\mathrm{C}^{+}$particles mainly came from the strike lines due to sputtering. Since $\mathrm{C}^{0}$ and $\mathrm{C}^{+}$particles were produced in the multistep dissociation and ionization chains of $\mathrm{CH}$ molecules, they usually had a deeper penetration depth. During $\mathrm{CH}_{4}$ injection, the $\mathrm{CH}$ molecules, $\mathrm{C}^{0}$ and $\mathrm{C}^{+}$particles were mainly from the dissociation and ionization of the injected $\mathrm{CH}_{4}$, which can be seen from the dramatically increase of their spectrum intensity during $\mathrm{CH}_{4}$ injection. In the other side, the $\mathrm{CH}_{4}$ gas injection cooled down the local plasma and modified the intrinsic particle distributions in the edge plasma. The $\mathrm{CH}$ penetration depth during $\mathrm{CH}_{4}$ injection was about $1.5 \mathrm{~cm}$ as shown in Fig.7(b).

The fifth nozzle which injected $\mathrm{CH}_{4}$ was in the same flux tube with a position between the $4^{\text {th }}$ and $5^{\text {th }}$ Langmuir probes. Therefore, we use the average measurement of these two probes to present the plasma parameters at the fifth nozzle. During $\mathrm{CH}_{4}$ injection, the electron temperature had a $\Delta \mathrm{T}_{\mathrm{e}} \approx 8$

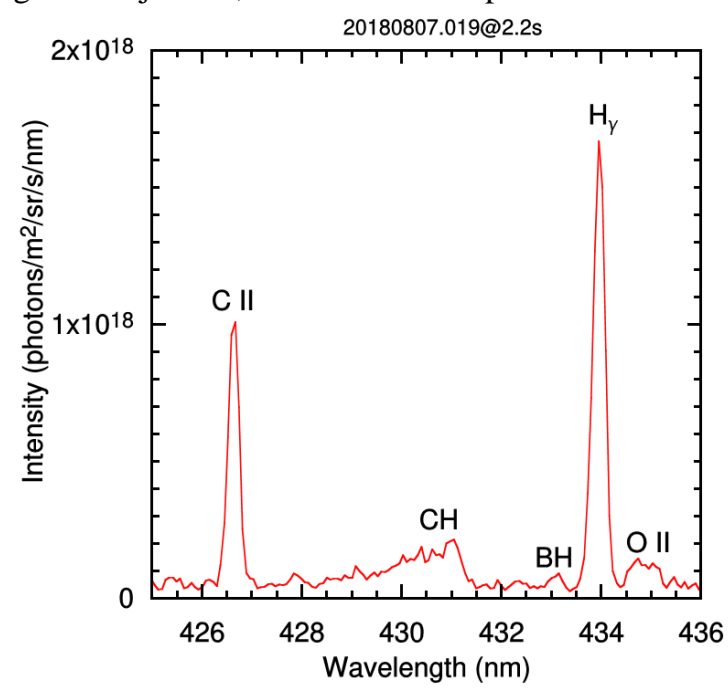

Figure 9. Typical spectrum of $\mathrm{CH}$ Gerö band measured in a hydrogen dishcarge with injecting power $P_{E C R H}=2.3 \mathrm{MW}$ and line integrated density is $n_{e}=7.4 e 19 \mathrm{~m}^{-2}$. 
$\mathrm{eV}$ decline due to the cooling effect, and the electron density only had a clear increase of $\Delta \mathrm{n}_{\mathrm{e}} \approx 1 \mathrm{e} 18 \mathrm{~m}^{-3}$ in the third $\mathrm{CH}_{4}$ injection as shown in Fig.8.

In the calculation, the spectrum integrated range for $\mathrm{CH}$ Gerö band was $\Delta \lambda=431.5 \mathrm{~nm}-430.0 \mathrm{~nm}=1.5 \mathrm{~nm}$ which was approximately proportional to the full band integration. The fraction factor of the integrated emission range to the full A$\mathrm{X}$ band integration was about $f_{A^{2} \Delta \rightarrow X^{2} \Pi}^{\Delta \lambda(430-431.5 n m)}=0.36$. This definition has been widely used in other fusion devices [4-7]. The experimentally determined effective $\mathrm{D} / \mathrm{XB}$ of the $\mathrm{A}-\mathrm{X}$ band of $\mathrm{CH}$ resulting from $\mathrm{CH}_{4}$ was $\left[\frac{D}{X B}\right]_{A^{2} \Delta \rightarrow X^{2} \Pi}^{C H_{4} \rightarrow C H}=16$ at the edge plasma parameters: $\mathrm{T}_{\mathrm{e}} \approx 20 \mathrm{eV}$ and $\mathrm{n}_{\mathrm{e}} \approx 5 \mathrm{e} 18 \mathrm{~m}^{-3}$ as shown in Fig.8. Here, the effective $\mathrm{D} / \mathrm{XB}$ included spectrometer geometry effect. In addition, $\mathrm{CH}$ molecules mainly came from the injected $\mathrm{CH}_{4}$ through dissociation chains and might also from recycling. Therefore, these effects should also be included in the effective D/XB. The transport losses of injected $\mathrm{CH}_{4}$ particles out of the viewing volume were assumed to be negligibly small. This value was slightly smaller compared to the measurements in other fusion devices, e.g. 55 and 4-20 in ASDEX Upgrade, 32-100 on TEXTOR, and 39 on DIII-D (Table 2 in ref.4). A further insight of the photon efficiencies will be obtained by simulations with the ERO code in future. Meanwhile, in our experiment, it seemed excessive $\mathrm{CH}_{4}$ injection which cooled down the local plasma dramatically. In addition, the Langmuir probes had a distance to the nozzles in toroidal direction as shown in Fig.2. Therefore, their electron temperature measurements might be higher than that at the nozzles due to the different cooling effect of injected $\mathrm{CH}_{4}$ in toroidal direction, which means the electron temperature at nozzles might be lower than $20 \mathrm{eV}$ in the experiment.

Fig.9 shows a typical spectrum of intrinsic $\mathrm{CH}$ molecules measured after boronization. The deduced $\mathrm{CH}_{4}$ particle flux $\Gamma^{\mathrm{CH} 4}$ was $1 \mathrm{e} 20 \mathrm{~m}^{-2} \mathrm{~s}^{-1}$ and flux ratio $\Gamma^{\mathrm{CH} 4} / \Gamma^{\mathrm{H}}$ was 0.02 by applying $\mathrm{D} / \mathrm{XB}(\mathrm{CH})=16$ and $\mathrm{S} / \mathrm{XB}\left(\mathrm{H}_{\gamma}\right)=1000$. The $\mathrm{S} / \mathrm{XB}$ of $\mathrm{H}_{\gamma}$ was adopted from Ref.17 which took into account molecular sources. The hydrocarbon particles were mainly produced at the strike line region because the boron films at strike lines only sustained several shots. Therefore, the $\mathrm{CH}_{4}$ particle flux at strike line region should be much larger than the deduced average values. In the other side, $\mathrm{CH}$ radicals not only originated from $\mathrm{CH}_{4}$, but also from heavier hydrocarbons such as $\mathrm{C}_{2} \mathrm{H}_{6}$, which could make an overestimate of $\mathrm{CH}_{4}$ particle flux. The hydrogen atoms were from the whole viewing plasma volume due to molecular hydrogen dissociation and released neutral hydrogen.

\section{Conclusions}

In OP1.2b of W7-X, the main plasma-facing components were made of graphite, which included graphite divertor plates, baffles, shields, and poloidal closures. The divertor spectrometer measurements showed that the principal impurities were $\mathrm{He}, \mathrm{C}$ and $\mathrm{O}$ in the plasma. Helium came from the wall conditioning, i.e. helium glow discharges and helium ECRH cleaning. The helium cannot be removed completely by hydrogen discharges. Oxygen originated from the vapor which was contained in the fine grain graphite. The existence of $\mathrm{He}$ and $\mathrm{O}$ in plasma made a significant contribution to the overall carbon erosion through enhanced physical and chemical sputtering. In order to improve the wall condition, especially reduce the oxygen content, a widely used oxygen getting technique, i.e. boronization, was applied through $10 \%$ $\mathrm{B}_{2} \mathrm{H}_{6}+90 \% \mathrm{He}$ in glow discharges in OP1.2b. After boronization, thin boron films were deposited on the plasma facing components, which results in the significant decrease of impurity level and total radiation power in plasma.

In order to quantify the carbon chemical erosion by hydrogen, $\mathrm{CH}_{4}$ injection experiment was applied on W7-X. The spectrum of its break-up products, i.e. $\mathrm{CH}$ Gerö band $\left(A^{2} \Delta \rightarrow X^{2} \Pi\right.$ ), was measured and applied to deduce the photon efficiency. The deduced effective $\mathrm{D} / \mathrm{XB}$ of $\mathrm{CH}$ for $\mathrm{CH}_{4}$ was 16 at the electron temperature $\mathrm{T}_{\mathrm{e}} \approx 20 \mathrm{eV}$ and density $\mathrm{n}_{\mathrm{e}}$ $\approx 5 \mathrm{e} 18$. However, it should be kept in mind that the intrinsic $\mathrm{CH}_{4}$ was mainly produced at the strike line and deposition region after boronization in $\mathrm{W} 7-\mathrm{X}$. In addition, the $\mathrm{CH}$ particles were not only from the dissociation of $\mathrm{CH}_{4}$, but also from heavier hydrocarbon.

\section{Acknowledgements}

This work has been carried out within the framework of the Eurofusion Consortium and has received funding from the Euratom research and training programme 2014-2018 and 2019-2020 under grant agreement No. 633053. The views and opinions expressed herein do not necessarily reflect those of the European Commision.

\section{References}

[1] Federici G, Skinner C H, Brooks J N, Coad J P, Grisolia C, Haasz A A, Hassanein A, Philipps V, Pitcher C S, Roth J, Wampler W R and Whyte D G 2001 Nucl. Fusion 411967

[2] Winter J 1996 Plasma Phys. Control Fusion 381503

[3] Winter J, Esser H G, Koenen L, Philipps V, Reimer H, Seggern J V, Schlueter J, Vietzke E, Waelbroeck F, Wienhold P, Banno T, Ringer D and Veprek S 1989 J. Nucl. Mater. 162-164 713

[4] Brezinsek S, Pospieszczyk A, Borodin D, Stamp M F, Pugno R, Mclean A G, Fantz U, Manhard A, Kallenbach A, Brooks N H, Groth M, Mertens Ph, Philipps V and Samm U, 2007 J. Nucl. Mater. 363-365 1119

[5] Brezinsek S, Pospieszczyk A, Stamp M F, Meigs A, Kirschner A, Huber A, Mertens Ph and JET contributors $2005 \mathrm{~J}$. Nucl. Mater. 337-339 1058

[6] Isler R C, Colchin R J, Brooks N H, Evans T E, West W P and Whyte D G 2001 Phys.Plasmas 84470 
[7] Brezinsek S, Pugno R, Fantz U, Manhard A, Mueller H W, Kallenbach A, Mertens Ph and ASDEX Upgrade team 2007 Phys. Scr. T128

[8] Renner H, Boscary J, Greuner H, Grote H, Hoffmann F W, Kisslinger J, Strumberger E and Mendelevitch B 2002 Plasma Phys. Control. Fusion 441005

[9] Wauters T, Goriaev A, Alonso A, Baldzuhn J, Brakel R, Brezinsek S, Dinklage A, Grote H, Fellinger J, Ford O P, Koenig R, Laqua H, Matveev D, Stange T, Vano L and W7-X team 2018 Nucl. Mater. Energy 17235

[10] Wei Y L, Wang E H, Liang Y, Brezinsek S, Schweer B, Krychowiak M, Neubauer O, Koenig R, Sereda S, Linsmeier Ch and W7-X team 2018 AIP Advances 8085011

[11] Barbui T, Krychowiak M, Roenig R, Schmitz O, Munoz Burgos J M, Schweer B, Terra A and W7-X team 2016 Rev. Sci. Instrum 87 11E554

[12] Laude R, Laux M, Ye M Y, Greuner H and Lindig S 2011 Fusion Eng. Des. 861133

[13] Zhang D, Koenig R, Feng Y, Burhenn R, Brezinsek S, Jakubowski M, Buttenschön B, Niemann H, Pavone A, Krychowiak M, Kwak S, Svensson J, Gao Y, Pedersen T S, Alonso A, Baldzuhn J, Beidler C D, Biedermann C, Bozhenkov S, Brunner K J, Damm H, Hirsch M, Giannone L, Drewelow P, Effenberg F, Fuchert G, Hammond K C, Hfel U, Killer C, Knauer J, Laqua H P,Laube R, Pablant N, Pasch E, Penzel F, Rahbarnia K, Reimold F, Thomsen H, Winters V, Wagner F and Klinger T 2019 Phys. Rev. Lett. 123025002

[14] Behringer K, Summers H P, Denne B, Forrest M and Stamp M 1989 Plasma Phys. Control Fusion 312059

[15] www.adas.ac.uk

[16] Nakano T, Higashijima S, Kubo H, Asakura N and Fukumoto M 2014 Nucl. Fusion 54043004

[17] Pospieszczyk A, Philipps V, Casarotto E, Koegler U, Schweer B, Unterberg B and Weschenfelder F 1997 J. Nucl. Mater. 241243833 